\title{
Erratum to: Going beyond the Beauty - Trust Link: the Moderating Role of Mood
}

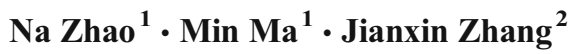

Published online: 28 November 2016

(C) Springer Science+Business Media New York 2016

\section{Erratum to: Curr Psychol}

DOI 10.1007/s12144-016-9481-8

The original version of this article unfortunately contained a mistake. The name of the second author was incorrectly listed as Mamin, when it is actually Min Ma. The correct information is as shown above.

The original article was corrected.

The online version of the original article can be found at http://dx.doi. org/10.1007/s12144-016-9481-8.

$\triangle \quad \mathrm{Na}$ Zhao

zhaoeve@126.com

Min Ma

mamin_psych@163.com

Jianxin Zhang

zhangjx@psych.ac.cn

1 School of Sociology and Psychology, Central University of Finance and Economics, 39 Xueyuan South Road, Haidian District, Beijing 100101, China

2 Key Laboratory of Mental Health, Institute of Psychology, Chinese Academy of Sciences, Beijing, China 